\title{
The Influence of Design and Definition on the Proportion of General Epilepsy Cohorts with Remission and Intractability
}

\author{
Seye Abimbola Alexandra L.C. Martiniuk Maree L. Hackett Craig S. Anderson \\ Neurological and Mental Health Division, George Institute for Global Health, and Sydney Medical School, \\ University of Sydney, Sydney, N.S.W., Australia
}

Key Words

Seizures $\cdot$ Remission $\cdot$ Intractability $\cdot$ Epilepsy $\cdot$ Cohorts

\begin{abstract}
Remission while on anti-epileptic drug (AED) therapy and remission off $A E D$ are the only prognostic criteria defined by the International League against Epilepsy (ILAE), defining remission as 5 seizure-free years. Prognosis studies in epilepsy have investigated other prognostic categories using different designs and definitions. This systematic review explores factors that explain discrepancies in the proportion of patients reported with commonly studied prognostic categories in general epilepsy cohorts. Thirty publications (reporting 37 studies) were included. The outcome categories were classified as immediate remission (5 studies), remission off medication (7 studies), remission on or off medication (15 studies), intractability (9 studies) and no remission after relapse (1 study). The findings show the importance of qualifying estimates specifically by how they were defined in each study, study design, setting and patient population as these have implications for patient management and counselling. The ILAE should define the outcome measures and terminology to which researchers should be required to adhere in subsequent updates of their guidelines on research related to remission and intractability.
\end{abstract}

Copyright $\odot 2011$ S. Karger AG, Basel

\section{Introduction}

The International League against Epilepsy (ILAE) makes methodological recommendations for studies in epilepsy with guidelines for assessing epidemiological variables, especially prevalence and incidence $[1,2]$. The only prognostic criteria defined by the ILAE are remission on medication and remission off medication, with the definition of remission as experiencing 5 seizure-free years. The ILAE also proposes long-term prospective, population-based studies of accurately diagnosed and classified incident cases, with a suggestion for studies of intractability once appropriate definitions are developed [2]. However, most of the prognosis studies in epilepsy have investigated these and other prognostic categories using different designs and definitions. This paper reviews the impact of factors such as study design and definitions of outcome on the proportion of patients with commonly studied prognostic categories in general epilepsy cohorts. The findings may help inform subsequent ILAE guidelines for prognosis studies in epilepsy. The knowledge of factors introducing bias into estimates in each study may also help inform patient management and counselling.

\section{KARGER}

Fax +41613061234 E-Mail karger@karger.ch www.karger.com
Seye Abimbola, MD, MPhil

National Primary Health Care Development Agency

Plot 681/682, Port-Harcourt Crescent, off Gimbiya Street

Area 11, Garki, Abuja, FCT (Nigeria)

Tel. +234 7039606 705, E-Mail seyeabimbola@ hotmail.com 
Fig. 1. Flow diagram of the review on the influence of design and definition on the proportion of general epilepsy cohorts with remission and intractability.

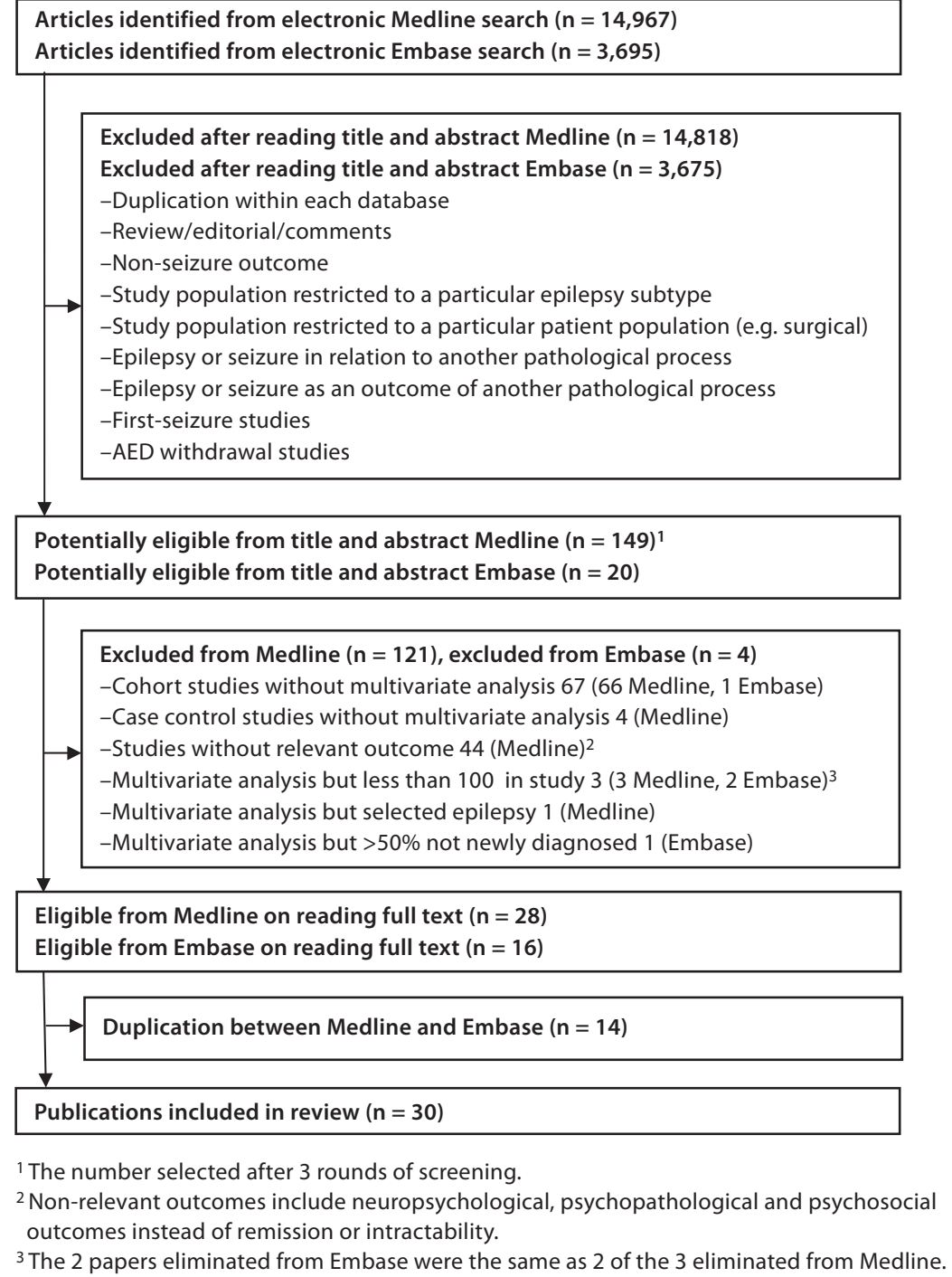

\section{Methods}

\section{Eligibility Criteria}

English language publications reporting general epilepsy cohort studies of at least 100 participants with newly diagnosed epilepsy and at least 1 year of follow-up were eligible. The authors of included studies had to attempt to identify independent predictors of remission and intractability in people with newly diagnosed epilepsy, therefore only studies with multivariate analysis were included. This effectively limits studies available in the literature to an unbiased sample.

\section{Search Strategy}

The search strategy [3] was selected to optimise the yield of prognostic studies in Medline [incidence (MeSH) OR explode mortality OR follow-up studies (MeSH) OR prognos* (text word) OR predict* (text word) OR course (text word)]. This was combined with [explode epilepsy (MeSH) OR explode seizure (MeSH) OR seizure disorder (text word)] using the boolean AND. Text words [multivariate (text word) OR multivariable OR regression (text word)] [4] were combined using the boolean AND with [explode epilepsy (Emtree) OR epilepsy (text word)] for Embase. The search was for publications archived in both databases up to March 2010. The full list of titles and corresponding abstracts from Medline and Embase was independently screened for eligible papers by 2 reviewers. Following the first round of selection based on inclusion and exclusion criteria (fig. 1), one reviewer conducted an additional screening of titles and abstracts to ensure completeness. The list of references of each potentially eligible paper was also manually searched. 


\section{Definitions}

'Newly diagnosed epilepsy' was defined as epilepsy within the first year for the purpose of this review. The 'unit of analysis' is individual studies from cohorts and not publications; a cohort could include different studies presented in different (or in the same) reports. Most studies refer to 'uncontrolled seizures' using the term 'intractable' or 'refractory' while some use both terms interchangeably [5-12]. The definition of 'intractability' is usually a variation on 'failure, for lack of seizure control, of more than 2 first-line anti-epileptic drugs (AED) with an average of more than 1 seizure per month for 18 months (some 2 years) and more than 3 consecutive months seizure-free during that interval' [12]. This definition of intractability and close variations on it were adopted in this review. The term 'refractory' is used to denote the category of patients who had not achieved at least 1 seizure-free year (remission) immediately before the last assessment [13-16]. Therefore 'refractory' also includes patients with intractable seizures.

\section{Data Extraction}

Data from each study were independently extracted 3 times; at each succeeding stage, the extracted data were compared with the previous extraction and where there were discrepancies, clarifications made by consulting the publication. Extracted data included authors and title of study, year of publication, journal, study design, age range (including mean and standard deviation), study recruitment period, length of reported follow-up, epilepsy subtypes included or excluded, investigated seizure outcome measures, and details of AED treatment and withdrawal, and how decisions about AED and the choice of drug were made. All data were extracted from the published studies, including related publications that authors refer to, especially for details of study population and methods. The authors were not contacted for further information.

\section{Results}

Figure 1 shows the flow diagram for the papers included in this systematic review. We included 38 eligible studies from 22 cohorts (table 1): 19 studies from 9 European cohorts, and 11 studies from 7 North American cohorts. Eight (36\%) out of a total of 22 unique cohorts were population based; 5 of the population-based cohorts were European (out of 10) while 3 were based in North America (out of 7). One cohort, originally from the MESS trial (MRC Multicentre Trial for Early Epilepsy and Single Seizures) [17] was multinational from 9 European and 2 South American countries, India and Israel although $50 \%$ of the cohort was from the UK. Two cohorts were from low- and middle-income countries (Bangladesh and India), 2 from Hong Kong and 1 from Saudi Arabia. There was a cohort formed from mixing 2 earlier cohorts, which were also included in this review [18]. No cohort was based in Australasia or Africa.
Thirty publications (reporting 37 studies) were included. Based on the outcome considered in the studies arising from each cohort, outcome categories were classified as immediate remission (5 studies), remission off medication (7 studies), remission on or off medication (15 studies), intractability ( 9 studies) and no remission after relapse (1 study). However, as only 1 study [19] reported on the proportion of patients with 'no remission after relapse', this outcome category was not included in the analysis. Table 1 shows the relationships between cohorts, publications, studies and corresponding outcome categories.

\section{Immediate Remission}

Five studies reported the proportion of patients with immediate remission as shown in table 2, ranging from 33 to $58 \%$. The studies employed different approaches to AED therapy. Two studies $[20,21]$ had all the patients in the cohort placed initially on antiepileptic monotherapy. One study [22] randomised treatment. For 2 studies, treatment and choice of drugs was at the discretion of the physician ( $80 \%$ on medication in one [23] and $44 \%$ in the other [24]).

\section{Remission off Antiepileptic Medication}

The 7 studies (table 3 ) reporting the proportion of patients in remission off AED were all in childhood cohorts, and the proportion ranged from 47 to $65 \%$.

\section{Remission on or off Medication}

Of 15 eligible studies on remission on or off medication, 13 reported on the proportion of patients with or without refractory seizures. The studies were categorised according to how the authors defined remission. Eight studies (table 4) described their outcome, ranging from 50 to $76 \%$, as 'terminal remission' (number of seizure-free months or years immediately before the last follow-up).

Seven studies defined remission by the 'seizure-free period during follow up', which may or may not be terminal. Two $[32,33]$ of the studies however did not present the proportion of patients in remission. Of the 5 (table 5) that presented the proportion, it ranged from 51 to $80 \%$.

\section{Intractability}

Nine studies, all conducted in childhood cohorts, were eligible, of which 7 reported the proportion of patients with intractable seizures, ranging widely from 7 to $33 \%$, as shown in table 6. 
Table 1. Descriptive characteristics of cohorts, publications and studies included in the review on the influence of design and definition on the proportion of general epilepsy cohorts with remission and intractability

\begin{tabular}{|c|c|c|c|c|c|}
\hline $\begin{array}{l}\text { Cohort recruitment and } \\
\text { period setting }\end{array}$ & $\begin{array}{l}\text { Age of } \\
\text { population }\end{array}$ & Study design & Number & Seizure outcome & Publication \\
\hline $\begin{array}{l}\text { Turku, Finland, } \\
\text { 1961-1964, population }\end{array}$ & $\begin{array}{l}\text { children } \\
\text { (<15 years) }\end{array}$ & $\begin{array}{l}\text { mixed } \\
\text { mixed } \\
\text { mixed } \\
\text { mixed } \\
\text { prospective } \\
\text { prospective } \\
\text { prospective }\end{array}$ & $\begin{array}{l}182(76.4 \%) \\
178(77.5 \%) \\
176(64.0 \%) \\
176(47.0 \%) \\
117(56.0 \%) \\
144(13.9 \%) \\
102(76.0 \%) \\
\end{array}$ & $\begin{array}{l}\text { remission on or off AED } \\
\text { remission on or off AED } \\
\text { remission on or off AED } \\
\text { remission off AED } \\
\text { remission off AED } \\
\text { remission after relapse } \\
\text { remission on or off AED }\end{array}$ & $\begin{array}{l}\text { Sillanpaa [31], } 1990 \\
\text { Sillanpaa [11], 1993 } \\
\text { Sillanpaa et al. [25], } 1998 \\
\text { Sillanpaa et al. [25], } 1998 \\
\text { Sillanpaa et al. [25], } 1998 \\
\text { Sillanpaa and Schmidt [52], } 2006 \\
\text { Sillanpaa et al. [19], 2009 }\end{array}$ \\
\hline $\begin{array}{l}\text { DSEC, the Netherlands, } \\
\text { 1988-1992, hospital }\end{array}$ & $\begin{array}{l}\text { children } \\
(<16 \text { years })\end{array}$ & $\begin{array}{l}\text { prospective } \\
\text { prospective } \\
\text { prospective }\end{array}$ & $\begin{array}{l}466(68.7 \%) \\
453(76.0 \%) \\
453(65.0 \%) \\
\end{array}$ & $\begin{array}{l}\text { remission on or off AED } \\
\text { remission on or off AED } \\
\text { remission off AED }\end{array}$ & $\begin{array}{l}\text { Arts et al. [28], } 1999 \\
\text { Arts et al. [30], } 2004 \\
\text { Geelhoed et al. [18], } 2005\end{array}$ \\
\hline $\begin{array}{l}\text { NGPSE, UK, } \\
\text { 1984-1987, population }\end{array}$ & $\begin{array}{l}\text { children and } \\
\text { adults (>5 years) }\end{array}$ & prospective & 289 (NS) & remission on or off AED & MacDonald et al. [33], 2000 \\
\hline $\begin{array}{l}\text { MESS, UK (50\%), } \\
\text { 1993-2000, hospital }\end{array}$ & $\begin{array}{l}\text { children and } \\
\text { adults }\end{array}$ & mixed & $1,443(57.5 \%)$ & early remission & Kim et al. [22], 2006 \\
\hline $\begin{array}{l}\text { CGSE, Italy, } \\
\text { 1982-1985, hospital }\end{array}$ & $\begin{array}{l}\text { children and } \\
\text { adults }\end{array}$ & $\begin{array}{l}\text { mixed } \\
\text { mixed } \\
\text { mixed }\end{array}$ & $\begin{array}{l}283(48.0 \%) \\
280(67.5 \%) \\
280(51.1 \%)\end{array}$ & $\begin{array}{l}\text { early remission } \\
\text { remission on or off AED } \\
\text { remission on or off AED }\end{array}$ & $\begin{array}{l}\text { CGSE [20], } 1988 \\
\text { CGSE [36], } 1992 \\
\text { CGSE [36], } 1992\end{array}$ \\
\hline $\begin{array}{l}\text { Copparo, Italy, } \\
\text { 1964-1984, population }\end{array}$ & $\begin{array}{l}\text { children } \\
\text { (<19 years) }\end{array}$ & prospective & $222(14.0 \%)$ & intractability & Casetta et al. [6], 1999 \\
\hline $\begin{array}{l}\text { Bari and Monza, Italy, } \\
1989-1999, \text { hospital }\end{array}$ & $\begin{array}{l}\text { children and } \\
\text { adults }\end{array}$ & mixed & $352(33.0 \%)$ & early remission & Del Felice et al. [21], 2010 \\
\hline $\begin{array}{l}\text { Västerbotten, Sweden, } \\
\text { 1985-1987, population }\end{array}$ & adults & mixed & $107(42.0 \%)$ & early remission & Lindsten et al. [23], 2001 \\
\hline $\begin{array}{l}\text { Akershus, Norway, } \\
\text { 1987-1994, population }\end{array}$ & adults & retrospective & $669(72.5 \%)$ & remission on or off AED & Lossius et al. [29], 1999 \\
\hline $\begin{array}{l}\text { Almeria, Spain, } \\
\text { 1994-2004, hospital }\end{array}$ & $\begin{array}{l}\text { children } \\
\text { (<14 years) }\end{array}$ & mixed & $343(8.7 \%)$ & intractability & Ramos-Lizana et al. [10], 2009 \\
\hline $\begin{array}{l}\text { Nova Scotia, Canada, } \\
\text { 1977-1985, population }\end{array}$ & $\begin{array}{l}\text { children } \\
(<16 \text { years })\end{array}$ & $\begin{array}{l}\text { mixed } \\
\text { mixed }\end{array}$ & $\begin{array}{l}502(54.0 \%) \\
602(55.0 \%)\end{array}$ & $\begin{array}{l}\text { remission off AED } \\
\text { remission off AED }\end{array}$ & $\begin{array}{l}\text { Camfield et al. [26], } 1993 \\
\text { Geelhoed et al. [18], } 2005\end{array}$ \\
\hline $\begin{array}{l}\text { Combination of DSEC and } \\
\text { Nova Scotia Cohorts }\end{array}$ & $\begin{array}{l}\text { children } \\
(<16 \text { years })\end{array}$ & mixed & $1,055(59.0 \%)$ & remission off AED & Geelhoed et al. [18], 2005 \\
\hline $\begin{array}{l}\text { Montreal, Canada, } \\
\text { 1991-2000, hospital }\end{array}$ & $\begin{array}{l}\text { children } \\
\text { ( } 2-17 \text { years })\end{array}$ & $\begin{array}{l}\text { retrospective } \\
\text { retrospective } \\
\text { retrospective }\end{array}$ & $\begin{array}{l}196(52.0 \%) \\
196(12.8 \%) \\
196(6.9 \%)\end{array}$ & $\begin{array}{l}\text { remission off AED } \\
\text { intractability } \\
\text { intractability }\end{array}$ & $\begin{array}{l}\text { Oskoui et al. [9], } 2005 \\
\text { Oskoui et al. [9], } 2005 \\
\text { Oskoui et al. [9], } 2005\end{array}$ \\
\hline $\begin{array}{l}\text { New York, USA, } \\
\text { 1983-1993, hospital }\end{array}$ & $\begin{array}{l}\text { children } \\
\text { (<19 years) }\end{array}$ & prospective & $182(37.0 \%)$ & early remission & Shinnar et al. [24], 2000 \\
\hline $\begin{array}{l}\text { Connecticut, USA, } \\
\text { 1993-1997, population }\end{array}$ & $\begin{array}{l}\text { children } \\
(<15 \text { years })\end{array}$ & $\begin{array}{l}\text { prospective } \\
\text { prospective }\end{array}$ & $\begin{array}{l}599(10.0 \%) \\
594(74.0 \%)\end{array}$ & $\begin{array}{l}\text { intractability } \\
\text { remission on or off AED }\end{array}$ & $\begin{array}{l}\text { Berg et al. [5], } 2001 \\
\text { Berg et al. [35], } 2001\end{array}$ \\
\hline $\begin{array}{l}\text { Boston, USA, } \\
\text { NS, hospital }\end{array}$ & $\begin{array}{l}\text { children } \\
(<18 \text { years })\end{array}$ & retrospective & NS & intractability & Ko and Holmes [7], 1999 \\
\hline $\begin{array}{l}\text { Rochester, USA, } \\
\text { 1935-1978, population }\end{array}$ & $\begin{array}{l}\text { children and } \\
\text { adults }\end{array}$ & retrospective & 298 (NS) & remission on or off AED & Shafer et al. [32], 1988 \\
\hline $\begin{array}{l}\text { New Haven, USA, } \\
\text { NS, hospital }\end{array}$ & $\begin{array}{l}\text { children } \\
\text { (NS) }\end{array}$ & retrospective & $234(32.5 \%)$ & intractability & Berg et al. [12], 1996 \\
\hline $\begin{array}{l}\text { Hong Kong, China I, } \\
\text { 1997-NS, hospital }\end{array}$ & adults & mixed & $260(60.0 \%)$ & remission on or off AED & Hui et al. [16], 2007 \\
\hline $\begin{array}{l}\text { Hong Kong, China II, } \\
\text { 1982-1997, hospital }\end{array}$ & $\begin{array}{l}\text { children and } \\
\text { adults }\end{array}$ & mixed & $301(14.2 \%)$ & intractability & Kwong et al. [8], 2003 \\
\hline $\begin{array}{l}\text { Riyadh, Saudi Arabia, } \\
\text { 1994-1996, hospital }\end{array}$ & adults & mixed & $826(80.0 \%)$ & remission on or off AED & Abduljabbar et al. [34], 1998 \\
\hline $\begin{array}{l}\text { Dhaka, Bangladesh, } \\
\text { 1996-NS, hospital }\end{array}$ & $\begin{array}{l}\text { children } \\
(<15 \text { years })\end{array}$ & retrospective & $151(49.7 \%)$ & remission on or off AED & Banu et al. [27], 2003 \\
\hline $\begin{array}{l}\text { New Delhi, India, } \\
\text { NS, hospital }\end{array}$ & $\begin{array}{l}\text { children } \\
\text { (NS) }\end{array}$ & mixed & NS & intractability & Chawla et al. [53], 2002 \\
\hline
\end{tabular}

Proportions with outcome (in percent) are given in parentheses. Mixed cohort = Combined prospective and retrospective case ascertainment; NS = not stated; DSEC = Dutch Study of Epilepsy in Childhood; NGPSE = National General Practice Study of Epilepsy; MESS = Multicentre Study of Early Epilepsy in Single Seizures; CGSE = Collaborative Group for the Study of Epilepsy. 
Table 2. Proportion of patients in immediate remission at 2 years by the proportion of patients on AED

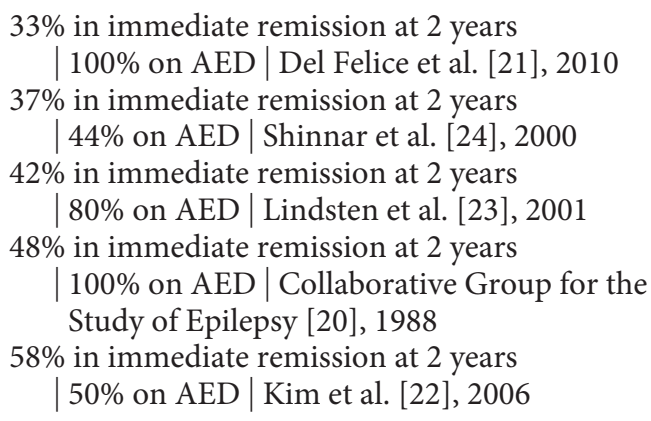

\section{Discussion}

\section{Immediate Remission}

The different approaches to treatment in the cohorts that reported immediate remission (table 2) were not reflected in the proportion of patients that achieved the outcome $[24,37]$. This may be a long-term outcome as medication suppresses seizures in the short term $[22,38$ 41]. However, 3 factors were important in explaining differences in the proportion of patients who entered immediate remission: case ascertainment, inclusion criteria and the age of patients within the cohort.

Where there was exclusive prospective case ascertainment (all patients identified at the exact point of second seizure), fewer patients (37\%) did not experience a next seizure after 2 years [24] compared to between 42 and $58 \%$ in 3 of the 4 studies with mixed case ascertainment $[20,22,23]$, especially including different proportions of first-seizure, prospectively identified and retrospectively ascertained patients. The proportion of the cohort with immediate remission was highest (58\%) where more than half of the patients were single-seizure patients [22]. In the other 2 cohorts [24,37], single-seizure cases were less than a third of the cohort. This supports the evidence that for some patients, the rate of seizure recurrence increases with increasing number of seizures [42-44].

However, among the cohorts with mixed retrospective and prospective case identification, 2 hospital-based studies with similar proportions of patients in each seizure category (the ratio of first seizure to $2-5$ seizures and $>5$ seizures being 4:9:7 in both studies) had widely divergent proportions of patients in immediate remission at 2 years of follow-up: it was $48 \%$ in one [20] and only $33 \%$ in the other [21]. Possible explanations include:
Table 3. Proportion of patients in remission off AED arranged according to potential for bias

52\% retrospective $\mid$ hospital $\mid$ off AED at last follow-up | Oskoui et al. [9], 2005

$47 \%$ mixed | population 5 years off AED at last follow-up

| Sillanpaa et al. [25], $1998^{1}$

$54 \%$ mixed | population | off AED at last follow-up

| Camfield et al. [26], 1993

$55 \%$ mixed | population | off AED at last follow-up

Geelhoed et al. [18], 2005

$59 \%$ mixed/prospective | population/hospital

| off AED at last follow-up | Geelhoed et al. [18], 2005

$65 \%$ prospective $\mid$ hospital $\mid$ off AED at last follow-up

| Geelhoed et al. [18], 2005

$56 \%$ prospective | population $\mid 5$ years off AED at last follow-up

| Sillanpaa et al. [25], $1998^{1}$

${ }^{1}$ Physicians were reluctant to discontinue AED.

Table 4. Remission as seizure-free period immediately before last assessment, i.e. terminal remission (TR)

$50 \%-3$ months TR with 1 year minimum follow-up

| Banu et al. [27], 2003 (retrospective)

$69 \%-6$ months TR with 2 years minimum follow-up

| Arts et al. [28], 1999 (prospective)

$60 \%$ - 1 year TR with 1 year minimum follow-up

| Hui et al. [16], 2007 (mixed)

$73 \%$ - 1 year TR (length of follow-up not stated)

| Lossius et al. [29], 1999 (retrospective)

$76 \%$ - 1 year TR with 5 years minimum follow-up

| Arts et al. [30], 2004 (prospective)

$76 \%$ - 1 year TR with $>10$ years minimum follow-up

| Sillanpaa et al. [19], 2009 (prospective)

$76 \%-3$ years TR with $>20$ years minimum follow-up

Sillanpaa [31], 1990 (mixed)

$64 \%-5$ years TR with $>20$ years minimum follow-up

| Sillanpaa et al. [25], 1998 (mixed)

The Age Difference between the Cohorts. The cohort with $48 \%$ in immediate remission at 2 years had a mean age of 19 years while the cohort with $33 \%$ had a mean age of about 32 years suggesting that younger/childhood onset epilepsy may have a better prognosis than adult onset epilepsy [45], which may be due to more symptomatic epilepsy occurring in adult onset epilepsy [46, 47] and benign syndromes occurring more in childhood [48].

Inclusion Criteria in the Cohorts. The study with $48 \%$ of the cohort in immediate remission at 2 years excluded 
Table 5. Remission (R) as seizure-free period during follow-up

80\% - 1 year R with 1 year minimum follow-up
| Abduljabbar et al. [34], 1998 (mixed)
$78 \%$ - 1 year R (during the last 10 of min. 20 years) follow-up
| Sillanpaa [11], 1993 (mixed)
$74 \%$ - 2 years R with 2 years minimum follow-up
$\mid$ Berg et al. [35], 2001 (prospective)
$68 \%$ - 2 years R by 5 years of follow-up
| Collaborative Group for the
Study of Epilepsy [36], 1992 (mixed)
$51 \%$ - 3 years R by 5 years of follow-up
| Collaborative Group for the
Study of Epilepsy [36], 1992 (mixed)

Table 6. Influence of definition and study design/setting on the proportion of patients with intractable seizures

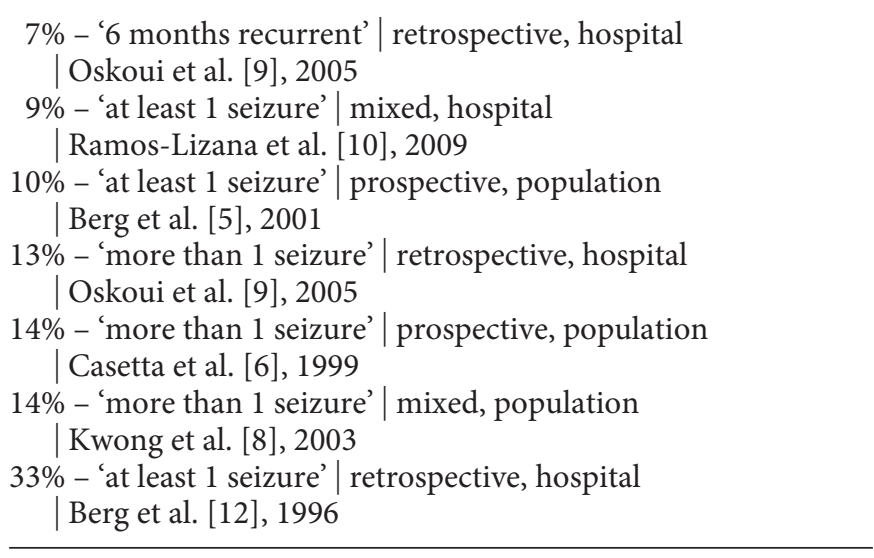

patients with progressive neurological disorders associated with an increased risk of seizures, e.g. brain tumour, while the cohort with $33 \%$ included every patient with newly diagnosed epilepsy.

The 2 studies $[20,22]$ that excluded patients with known poor prognosis compared to the other $3 \mathrm{had}$ a higher proportion of patients in immediate remission after 2 years (58 and $48 \%$ ). The study from a randomised controlled trial [22] (with 58\%) excluded all the patients for whom indication for AED therapy was certain, while the other study [20] (with 48\%) only excluded those with progressive neurological disorder. This finding also suggests that patients with known poor prognosis, or 'for whom indication to commence treatment was not clear', are more likely to have a recurrence after diagnosis.

The Proportion of General Epilepsy Cohorts with Remission and Intractability

\section{Remission off Antiepileptic Medication}

Three study factors were important in explaining the variation in the proportion of patients who were successfully weaned off AED: the study setting, the method of case ascertainment and the readiness of the treating physician to take patients off medication. If the proportions of patients in remission off medication at the last followup in the respective studies are arranged according to the hypothesis that prospective, population-based studies are the least likely to be biased, and retrospective, hospital-based studies are the most likely to be biased [49], the progression of the proportion of patients off AED is as expected, largely linear (table 3 ).

The less biased studies have a higher proportion of patients in remission off AED, except for 2 data points from the same cohort [25] where the definition of remission off AED was such that the patient had to have continued in remission off medication for at least 5 years. The relatively lower proportion of patients in remission off AED in the cohort may have been further accentuated by the fact that 3 seizures instead of 2 diagnosed epilepsy in the cohort and the physicians responsible for patients in the cohort were more reluctant to discontinue AED [50]. This finding suggests that in childhood onset epilepsy, more than two thirds of patients may be successfully weaned off AED.

The proportion with remission off AED was not affected by the fact that patients with generalised absence seizures and known poor prognosis, including progressive neurological disorders, were excluded from the cohort with 54\% in remission off medication [26] compared to $55 \%$ when the previously excluded patients were later included in the analysis [18]. Possibly, the two groups reintroduced into the cohort (good prognosis, i.e. generalised absence seizures, and poor prognosis) balance each other out and hence did not reflect in the proportions.

\section{Remission on or off Medication}

Four study factors were important in explaining the variation in the proportion of patients reported with remission on or off medication: the definition of remission, the length of follow-up, the study design and the age of patients within the cohort.

For the 8 studies that described their outcome as 'terminal remission', the proportion of the cohorts in remission varied according to the length of seizure-free period that defined terminal remission: the proportion in remission rises with duration of follow-up and falls with the length of the seizure-free period defining terminal remission (table 4). When it was 3 months of terminal remis-

Neuroepidemiology 2011;36:204-212 
sion with a 1-year minimum follow-up, the proportion in remission was $50 \%$ [27]. It rises to between 73 and $76 \%$, with $1-3$ years of terminal remission when the minimum follow-up ranged from 5 to 20 years [19,29-31], and drops to $64 \%$ when a 5 -year seizure-free period defined terminal remission, even though the minimum follow-up was 20 years [25]. For 2 largely prospective studies that defined terminal remission as a 1-year seizure-free period $[19,30]$, the proportion of patients in remission remained at $76 \%$ in spite of doubling (5 and 10 years) of the minimum length of follow-up between the 2 studies (table 4). These show that it takes time for people with newly diagnosed epilepsy to enter terminal remission; however, after a period, possibly 5 years, patients who will ultimately enter remission would have achieved the outcome.

However, Hui et al. [16], in a study of an adult cohort, had a lower proportion of patients in remission relative to all the other comparable studies conducted in childhood onset epilepsy. The proportion in remission for prospective studies was also higher than in comparable cohorts with mixed and retrospective case ascertainment. This agrees with the evidence that retrospective studies introduce bias to estimates of proportion of patients in remission [49] and that childhood onset epilepsy may have a better prognosis than adult onset epilepsy [45-48].

In the 5 studies that defined remission by the 'seizurefree period during follow up' and presented the proportion of those with the outcome, as expected the percentage of patients in remission decreased as the number of seizure-free years that defined remission increased (table 5). In these studies, the proportion of patients in remission was higher when compared with those that entered terminal remission for the same number of years and with a comparable length of follow-up. This is also an expected pattern as relapses may occur at any time to truncate terminal remission, whereas what is needed to satisfy the definition 'seizure-free period during followup' is one continuous stretch of the designated seizurefree period at any point during follow-up.

\section{Intractability}

Two factors explained the differences in the proportion of patients with medically intractable seizures in individual studies: the study design/setting and how intractability was defined. Medically intractable seizures are usually defined as having 'at least 1' or 'more than 1' seizure per month for about 1 year (ranged between at least 6 months and at least 2 years) after more than 2 AED trials singly or in combination, at the maximum tolerable dose [12].
However, studies that defined intractability as having ' 1 or more' seizures per month $[6,8,9]$ had more patients who met the criteria for intractability (13-14\%) compared to the studies $[5,10]$ that defined intractability as 'more than 1' seizure per month (9-10\%). There were 2 outliers, both from retrospective hospital-based cohorts: one that defined intractability as having recurrent seizures in the 6 months immediately before the last follow-up had 7\% [9] while the other, even though it defined intractability as having 'at least 1 ' or more seizures per month, had one third (32.5\%) of the cohort meeting the criteria for intractability [12].

\section{Conclusion}

Based on the results of these findings, we recommend that:

(1) Target population: future prognostic studies seeking to determine the proportion of patients with remission or intractability should prospectively recruit a population-based incident cohort, i.e. people with newly diagnosed epilepsy. Study populations selected by convenience are likely to bias study findings and overrepresent people with an ongoing need for management and underrepresent people with well-controlled epilepsy.

(2) Duration of follow-up: based on existing data, it appears that the optimal period of follow-up is about 5 years, beyond which it seems there is little or no change in the proportions of people with remission or intractability. However, given the dynamic nature of the prognosis of epilepsy, certain patients who have achieved remission may experience relapse, and some patients with intractability may ultimately experience remission. Thus, a follow-up beyond 5 years will help determine the proportion and predictors of patients in these cross-over categories, and should be encouraged where funding permits.

(3) Outcome measures: the status of 'terminal remission' (number of seizure-free months or years immediately before the last follow-up) is a more reliable and clinically relevant measure than 'seizure-free period during follow-up' and should be the preferred measure in future studies. Remission 'ever' tends to overestimate the proportion of patients in remission.

(4) Clear, a priori definitions: researchers referring to the proportion of patients with remission or intractability should explain how these estimates were defined in the study, the study design, study setting and patient population of the cohort. 
(5) Re-analysis of existing data: previous cohorts may consider the newly proposed ILAE definition of uncontrolled seizures, termed 'drug-resistant seizure' and defined as failure of adequate trials of 2 tolerated and appropriately chosen and used AED schedules (as monotherapies or in combination) to achieve sustained seizure freedom, determined after 1 year or 3 times the prior interseizure interval, whichever is longer [51]. It would be informative to see how results from re-analysis using the newly proposed ILAE definition of uncontrolled seizures compare to results from analyses using previous definitions of remission and intractability.

The ILAE in updating the guidelines for epidemiological research in epilepsy $[1,2]$ may need to define in detail the outcome measures and terminologies to which epidemiological studies will be required to adhere. The knowledge of factors introducing bias into estimates in each study is also important because this is often the only prognostic information that a physician may rely upon to make a decision on a patient's management strategy and how to counsel patients and their relatives. Though challenging, population-based studies with prospective case identification at the second seizure remain the ideal study design for prognosis studies in newly diagnosed epilepsy [49].

\section{Acknowledgements}

During the completion of this work S.A. was supported by the George Institute for Global Health and a Rotary Foundation Ambassadorial Scholarship, M.H. was in receipt of an NHMRC Career Development Award 632925 (2010-2014) and C.A. was in receipt of an NHMRC Research Fellowship (2008-2012) grant. Kathleen Bongiovanni (MIPH) assisted with screening citations.

\section{Disclosure Statement}

None of the authors report a conflict of interest.

\section{References}

1 Anonymous: Guidelines for epidemiologic studies on epilepsy. Commission on Epidemiology and Prognosis, International League against Epilepsy. Epilepsia 1993;34: 592-596.

$\checkmark 2$ Anonymous: ILAE Commission Report. The epidemiology of the epilepsies: future directions. International League against Epilepsy. Epilepsia 1997;38:614-618.

3 Wilczynski NL, Haynes RB, Hedges T: Developing optimal search strategies for detecting clinically sound prognostic studies in MEDLINE: an analytic survey. BMC Medi 2004;2:23.

-4 Furlan AD, Irvin E, Bombardier C: Limited search strategies were effective in finding relevant nonrandomized studies. J Clin Epidemiol 2006;59:1303-1311.

5 Berg AT, Shinnar S, Levy SR, Testa FM, Smith-Rapaport S, Beckerman B: Early development of intractable epilepsy in children: a prospective study. Neurology 2001; 56:1445-1452.

-6 Casetta I, Granieri E, Monetti VC, Gilli G, Tola MR, Paolino E, et al: Early predictors of intractability in childhood epilepsy: a community-based case-control study in Copparo, Italy. Acta Neurol Scand 1999;99:329333.

7 Ko TS, Holmes GL: EEG and clinical predictors of medically intractable childhood epilepsy. Clin Neurophysiol 1999;110:12451251.

The Proportion of General Epilepsy

Cohorts with Remission and Intractability
8 Kwong KL, Sung WY, Wong SN, So KT, et al: Early predictors of medical intractability in childhood epilepsy. Pediatr Neurol 2003;29: 46-52.

-9 Oskoui M, Webster RI, Zhang X, Shevell MI, et al: Factors predictive of outcome in childhood epilepsy. J Child Neurol 2005;20:898904.

10 Ramos-Lizana J, Aguilera-Lopez P, AguirreRodriguez J, Cassinello-Garcia E: Early prediction of refractory epilepsy in childhood. Seizure 2009;18:412-416.

11 Sillanpaa M: Remission of seizures and predictors of intractability in long-term followup. Epilepsia 1993;34:930-936.

$\checkmark 12$ Berg AT, Levy SR, Novotny EJ, Shinnar S: Predictors of intractable epilepsy in childhood: a case-control study. Epilepsia 1996; 37:24-30.

13 Semah F, Picot MC, Adam C, Broglin D, Arzimanoglou A, Bazin B, et al: Is the underlying cause of epilepsy a major prognostic factor for recurrence? Neurology 1998;51: 1256-1262.

14 Kwan P, Brodie MJ: Early identification of refractory epilepsy. N Engl J Med 2000;342: 314-319.

15 Stephen LJ, Kwan P, Brodie MJ: Does the cause of localisation-related epilepsy influence the response to antiepileptic drug treatment? Epilepsia 2001;42:357-362.

16 Hui ACF, Wong A, Wong HC, Man BL, AuYeung KM, Wong KS: Refractory epilepsy in a Chinese population. Clin Neurol Neurosurg 2007;109:672-675. $\checkmark 17$ Marson A, Jacoby A, Johnson A, Kim L, Gamble C, Chadwick D, et al: Immediate versus deferred antiepileptic drug treatment for early epilepsy and single seizures: a randomised controlled trial. Lancet 2005;365: 2007-2013.

$\rightarrow 18$ Geelhoed M, Boerrigter AO, Camfield P, Geerts AT, Arts W, Smith B, et al: The accuracy of outcome prediction models for childhood-onset epilepsy. Epilepsia 2005;46: 1526-1532.

$\checkmark 19$ Sillanpaa M, Schmidt D: Early seizure frequency and aetiology predict long-term medical outcome in childhood-onset epilepsy. Brain 2009;132:989-998.

20 Collaborative Group for the Study of Epilepsy: Prognosis of epilepsy in newly referred patients: a multicenter prospective study. Collaborative Group for the Study of Epilepsy. Epilepsia 1988;29:236-343.

21 Del Felice A, Beghi E, Boero G, La Neve A, Bogliun G, De Palo A, et al: Early versus late remission in a cohort of patients with newly diagnosed epilepsy. Epilepsia 2010;51:37-42.

22 Kim LG, Johnson TL, Marson AG, Chadwick DW, MRC MESS study group: Prediction of risk of seizure recurrence after a single seizure and early epilepsy: further results from the MESS trial. Lancet Neurol 2006;5:317322 (erratum published in Lancet Neurol 2006;5:383).

23 Lindsten H, Stenlund H, Forsgren L: Seizure recurrence in adults after a newly diagnosed unprovoked epileptic seizure. Acta Neurol Scand 2001;104:202-207. 
-24 Shinnar S, Berg AT, O’Dell C, Newstein D, Moshe SL, Hauser WA: Predictors of multiple seizures in a cohort of children prospectively followed from the time of their first unprovoked seizure. Ann Neurol 2000;48: 140-147.

-25 Sillanpaa M, Jalava M, Kaleva O, Shinnar S: Long-term prognosis of seizures with onset in childhood. N Engl J Med 1998;338:17151722.

26 Camfield C, Camfield P, Gordon K, Smith B, Dooley J: Outcome of childhood epilepsy: a population-based study with a simple predictive scoring system for those treated with medication. J Pediatr 1993;122:861-868.

-27 Banu SH, Khan NZ, Hossain M, Jahan A, Parveen M, Rahman N, et al: Profile of childhood epilepsy in Bangladesh. Dev Med Child Neurol 2003;45:477-482.

28 Arts WFM, Geerts AT, Brouwer OF, Peters ACB, Stroink H, Van Donselaar CA: The early prognosis of epilepsy in childhood: the prediction of a poor outcome. The Dutch Study of Epilepsy in Childhood. Epilepsia 1999;40:726-734.

29 Lossius MI, Stavem K, Gjerstad L: Predictors for recurrence of epileptic seizures in a general epilepsy population. Seizure 1999;8: 476-479.

- 30 Arts WFM, Brouwer OF, Peters ACB, Stroink H, Peeters EAJ, Schmitz PIM, et al: Course and prognosis of childhood epilepsy: 5 -year follow-up of the Dutch study of epilepsy in childhood. Brain 2004;127:17741784 .

-31 Sillanpaa M: Children with epilepsy as adults: outcome after 30 years of follow-up. Acta Paediatr Scand Suppl 1990;368:1-78.

- 32 Shafer SQ, Hauser WA, Annegers JF, Klass DW: EEG and other early predictors of epilepsy remission: a community study. Epilepsia 1988;29:590-600.
33 MacDonald BK, Johnson AL, Goodridge DM, Cockerell OC, Sander JW, Shorvon SD: Factors predicting prognosis of epilepsy after presentation with seizures. Ann Neurol 2000;48:833-841 (errata published in Ann Neurol 2001;49:547, 2001;50:830).

-34 Abduljabbar M, Ogunniyi A, Daif AK, AlTahan A, Al-Bunyan M, Al-Rajeh S: Epilepsy classification and factors associated with control in Saudi adult patients. Seizure 1998; 7:501-504.

35 Berg AT, Shinnar S, Levy SR, Testa FM, Smith-Rapaport S, Beckerman B, et al: Twoyear remission and subsequent relapse in children with newly diagnosed epilepsy. Epilepsia 2001;42:1553-1562.

36 Collaborative Group for the Study of Epilepsy: Prognosis of epilepsy in newly referred patients: a multicenter prospective study of the effects of monotherapy on the long-term course of epilepsy. Collaborative Group for the Study of Epilepsy. Epilepsia 1992;33:4551.

- 37 Hauser WA, Rich SS, Lee JR, Annegers JF Anderson VE: Risk of recurrent seizures after two unprovoked seizures. N Engl J Med 1998;338:429-434.

-38 Temkin NR, Dikmen SS, Anderson GD, Wilensky AJ, Holmes MD, Cohen W, et al: Valproate therapy for prevention of posttraumatic seizures: a randomized trial. J Neurosurg 1999;91:593-600.

- 39 Temkin NR, Dikmen SS, Wilensky AJ, Keihm J, Chabal S, Winn HR: A randomized, double-blind study of phenytoin for the prevention of post-traumatic seizures. N Engl J Med 1990;323:497-502.

40 Foy PM, Chadwick DW, Rajgopalan N, Johnson AL, Shaw MD: Do prophylactic anticonvulsant drugs alter the pattern of seizures after craniotomy? J Neurol Neurosurg Psychiatry 1992;55:753-757.

-41 Musicco M, Beghi E, Solari A, Viani F: Treatment of first tonic-clonic seizure does not improve the prognosis of epilepsy. First Seizure Trial Group (FIRST Group). Neurology 1997;49:991-998.
42 Elwes RDC, Johnson AL, Reynolds EH: The course of untreated epilepsy. Br Med J 1988; 297:948-950.

43 Reynolds EH: Do anticonvulsants alter the natural course of epilepsy? Treatment should be started as early as possible. Br Med J 1995; 310:176-177.

44 Hauser WA, Lee JR: Do seizures beget seizures? Prog Brain Res 2002;135:215-219.

45 Hippocrate: De la maladie sacrée, livre 6; in Littré E (ed): Oeuvres complètes d'Hippocrate. Paris, Baillière, 1849.

46 Nikanfar M, Arami MA, Mansourpoor L, Najmi S: Common etiologies of adult onset epilepsies in northwest of Iran. Acta Med Iran 2005;43:223-226.

47 Stephen LJ, Brodie MJ: Epilepsy in elderly people. Lancet 2000;355:1441-1446.

48 Shorvon S, Perucca E, Fish D, Dodson W (eds): The Treatment of Epilepsy, ed 2. Oxford, Blackwell, 2004.

49 Sander JW, Shorvon SD: Incidence and prevalence studies in epilepsy and their methodological problems: a review. J Neurol Neurosurg Psychiatry 1987;50:829-839.

50 Sillanpaa M, Camfield P, Camfield C: Predicting long-term outcome of childhood epilepsy in Nova Scotia, Canada, and Turku, Finland: validation of a simple scoring system. Arch Neurol 1995;52:589-592.

51 Kwan P, Arzimanoglou A, Berg AT, Brodie MJ, Allen Hauser W, Mathern G, et al: Definition of drug resistant epilepsy: consensus proposal by the ad hoc Task Force of the ILAE Commission on Therapeutic Strategies. Epilepsia 2010;51:1069-1077.

-52 Sillanpaa M, Schmidt D: Natural history of treated childhood-onset epilepsy: prospective, long-term population-based study. Brain 2006;129:617-624

-53 Chawla S, Aneja S, Kashyap R, Mallika V: Etiology and clinical predictors of intractable epilepsy. Pediatr Neurol 2002;27:186191. 